\title{
Involvement of Mitanins (female health volunteers) in active malaria surveillance, determinants and challenges in tribal populated malaria endemic villages of Chhattisgarh, India
}

\author{
Mehul Kumar Chourasia ${ }^{1}$, Kamaraju Raghavendra ${ }^{2^{*}}$, Rajendra Mohan Bhatt ${ }^{3}$, Dipak Kumar Swain ${ }^{1}$,
} G. D. P. Dutta ${ }^{3}$ and Immo Kleinschmidt ${ }^{4}$

\begin{abstract}
Background: Accredited Social Health Activists (ASHA), female health volunteers working at village level have become an integral component of National Health Mission (NHM) in India in the past two decades. Mitanin (meaning female friend in local dialect), a precursor of ASHA, play an indispensable role in early detection of health related problems and are helping in improving overall community health status in Chhattisgarh state. The current study was carried out to evaluate the feasibility of involving Mitanin in active malaria surveillance work in 80 tribal villages of Chhattisgarh and to explore the challenges and determinants to perform malaria surveillance activities by the Mitanins.
\end{abstract}

Methods: A total of 162 Mitanins were selected and divided into two age and village matched groups. The first group (training plus) of Mitanins were given additional training in malaria surveillance activities in whilst the second (standard) group received routine training. All Mitanins were interviewed using a structured questionnaire. In-depth interviews were also conducted among randomly selected sub groups of Mitanins (five from each group) after the completion of the quantitative survey. Performance of Mitanins was evaluated using pre-defined grading scores (A-E) which included various factors such as educational qualifications and knowledge about malaria, its signs and symptoms and knowledge, attitude and treatment practices.

Results: More number of Mitanins in training plus group has showed better performance $(\geq$ B) than those in the standard group of Mitanins (80\% vs 43.5\%, $p=0.001$ ) after adjusting for socio-demographic factors. Based on the outcome of in-depth interviews, Mitanin's lack of adequate support from supervisors, delayed payment of incentives and lack of appreciation were the major challenges mentioned.

Conclusion: Mitanins can play an effective role in active fever surveillance for malaria besides performing other health related tasks at sub-village level after focused education on malaria related activities and proper supervision.

Keywords: Mitanin, Asha, Active malaria surveillance, Chhattisgarh, India

\footnotetext{
* Correspondence: kamarajur2000@yahoo.com

${ }^{2}$ National Institute of Malaria Research (ICMR), Sector-8, Dwarka, New Delhi

110077, India

Full list of author information is available at the end of the article
} 


\section{Background}

Community Health Workers (CHW's) are the key component of the primary health care system in many countries. CHW's are examples of active community participation towards the betterment of the health of the community. Based on countries' need and demand it may differ in the levels of health care system within countries, states and regions but in general, their role and responsibility would be similar. This concept of community participation is primarily based on the principle that if members of communities' make an active effort towards their own and the community's well-being then they would be more responsive towards primary prevention and radical treatment. This awareness would lead to positive impact on the overall health of the society [1]. With this concept, governments involve community members in the primary health care system. Globally, they have been given a variety of names including Health Auxiliaries, Barefoot Doctors, Shasthyo Shebika, Health Promoters, Health Volunteers, Village Health Workers, Community Health Volunteers and Community Health Workers [2, 3].

The World Health Organization (WHO) describes CHWs as "men or women selected by the society and trained to deal with the ailment of individuals and the community and to work in close relationship with the health care services" [4].

The role of community participation in a range of malaria control activities has a long history in many malaria endemic countries [5, 6]. For example, Latin America's Volunteer Collaborator Networks (VCNs), unpaid community volunteers, was one of the oldest and successful examples of community participation in malaria control activities. They were trained and supervised by National Malaria Service members [7].

Accredited Social Health Activists (ASHA) and Auxiliary Nurse Midwifery (ANM) are formally trained to support health care system, especially in primary health centers to strengthen basic health services. These village-level community health workers called "ASHA" act as an interface between the community and the public health care system [8].

\section{Inception of Mitanin and ASHA programme in Chhattisgarh and India $[9,10]$}

In the early 70's, Government of India had first introduced the CHW Scheme in the country envisioning "provision of health services at the doorsteps of villager". However, this scheme was changed over time from CHW in 1977 to Community Health Volunteer in 1980 and Village Health Guides (VHG) in 1981. In 2002, under the ambit of Family Welfare Program, VHG Scheme was completely supported and funded by central government.
To improve access to health care and the health status of rural communities in Chhattisgarh, the state government together with civic society conceptualized and implemented the community health workers (CHWs) programme in 2002. This program was the precursor of ASHA and key reference to developing ASHA program across India. In 2005, CHW programme was merged into National Health Mission (NHM). ASHA workers were then recognized as 'Mitanin' in the state which means 'Female Friend' in the local dialect. Currently, the state has engaged a total of 69,000 Mitanins. Mitanin Programme is implemented and monitored by Department of Health and Family Welfare, Government of Chhattisgarh in collaboration with State Health Resource Center (SHRC). SHRC is responsible for imparting training to Mitanins in implementing various health programs few of which are incentive based.

\section{Rationale of the study}

ASHA and Mitanin reside in close proximity to the beneficiary's home, including services delivered at home or to the family and through outreach sessions. It is also expected that Mitanin can play an essential role in detecting problems at the earliest and help in improving overall community health status. In India, several studies have been conducted on various public health care programs related to maternal and child health such as immunization, Integrated Child Development Services, and Janani Suraksha Yojna (Safe Motherhood program) etc. [11-14]. Limited information is available related to ASHA's and Mitanins' (Female health volunteers) perception, knowledge and work performance related to malaria.

Multi-country project collaborated by WHO on Implication of Insecticide Resistance (IIR) was carried out in Keshkal, one of the tribal populated sub-districts of Kondagaon district of Chhattisgarh, India aiming to assess impact of insecticide resistance in malaria vectors in presence of Long Lasting Insecticide treated Nets (LLIN) and Indoor Residual spray (IRS) intervention in controlling malaria transmission in malaria endemic area [15]. In this project, Mitanins' were engaged to carry out surveillance in the selected households in the respective village. Mitanins working under IIR project were classified as 'IIR Mitanins'. While rest of the Mitanins in the study area were categorized as 'Non-IIR Mitanins'.

The current study was carried out with the following objectives:

1. To evaluate and compare the knowledge and quality of malaria surveillance work performed by Mitanins' engaged with IIR- India project in comparison to Mitanins not involved in the project activities (Non-IIR). 
2. To explore the effect of various socio-demographics factors such as age and education on malaria surveillance work of the study population

3. To find the various challenges faced by the Mitanins to performance their routine surveillance work related to Malaria

\section{Methods}

\section{Study area and study design}

The present study was carried out in 80 tribal populated villages of Chhattisgarh, India and 162 Mitanins were interviewed during October 2015 to February 2016. This study is a non-blinded randomized controlled trial (additional malaria training being the intervention), with a qualitative component in sub set of population.

\section{Study arms and subject selection}

Mitanins were recruited in two groups. The first group comprise of randomly selected 81 Mitanins (out of 124 Mitanins working under IIR project) with additional malaria training (training plus) and in second groups consist 81 Mitanins (were randomly selected from remaining 300 Non-IIR Mitanins) with routine training (standard). Second group Mitanins were age and villages matched with the group one Mitanins.

\section{Study intervention \\ Training on malaria surveillance}

Two full day basic training sessions on malaria control and surveillance were held in February-March 2015 with groups comprising of 5-15 Mitanins. These Mitanins comprised the training plus group. Basic and field training was imparted in both local dialect (Chhattisgarhi) and in Hindi. Thereafter, these trained IIR Mitanins were engaged for an additional responsibility of malaria fortnight surveillance in their respective villages selected for the IIR project. Their additional responsibility included house to house visit of the cohort children recruited in the IIR-India project. They were trained to collect data on the previous night's and previous week's fever history of the children, record temperature (axial), prepare blood slide from fever patients, use bivalent rapid diagnostic tests (RDTs) for detecting Plasmodium vivax $(P v)$ and $P$. falciparum $(P f)$ and to dispense antimalarial drugs to malaria positive cases following National Drug Policy. These surveillance activities were regularly monitored by Malaria Surveillance Workers (MSW's) hired and trained for malaria surveillance among non-cohort population in the IIR project villages and, and supervised by the project staff.

\section{Study methods}

\section{Quantitative component:}

Structured questionnaire based Interview.
Pre-tested interviewer administered structured questionnaires were used for the study. Study questionnaires were divided into 8 sections; first four sections focused on personal information, duties, selection methods and training, while sections 5-8 included knowledge about malaria, anti-malarial drugs, documentation, slides prepration and use of rapid diagnostic tests (RDTs). Quality of RDT use and blood smear preparation were routinely assessed by laboratory technicians based at the IIR Project site office and improved if needed.

\section{Evaluation and grading of Mitanins' performance}

Performance of Mitanins was evaluated using pre-defined grading scores (9 point grades) which included various factors such as educational qualifications and knowledge about malaria, including its signs and symptoms and treatment. Nine points score based performance was then converted in to grades from A-E (Table 1).

\section{Qualitative component: In-depth interviews}

Among all the study participants, purposefully those were selected who can best answer about the given research topic and enhance understanding about the challenges experienced by them. Total ten in-depth interviews (five candidates from each group) were conducted to explore the challenges and difficulties faced by the Mitanins. The topic of the interviews was "day to day challenges in Mitanins' work". All interviews were conducted in either Hindi and/or Chhattisgarhi (local dialect) by the trained investigators.

\begin{tabular}{|c|c|c|c|}
\hline Sl. no & Grading factor & Maximum score & Marking criteria \\
\hline 1 & Basic educational qualification & 01 & Yes - 1, No- 0 \\
\hline 2 & \multicolumn{3}{|l|}{$\begin{array}{l}\text { Level of knowledge about } \\
\text { malaria }\end{array}$} \\
\hline 2.a & Sign \& symptoms of malaria & 01 & Yes - 1, No- 0 \\
\hline 2.b & $\begin{array}{l}\text { Knowledge about malaria } \\
\text { control }\end{array}$ & 01 & Yes - 1, No- 0 \\
\hline 3 & Slide preparation & 01 & Yes - 1, No- 0 \\
\hline 4 & RDT preparation & 01 & Yes - 1, No- 0 \\
\hline 5 & \multicolumn{3}{|l|}{$\begin{array}{l}\text { Knowledge about anti-malarial } \\
\text { drugs }\end{array}$} \\
\hline 5.a & Treatment of $P v$ & 01 & Yes - 1, No- 0 \\
\hline 5.b & Treatment of $P f$ & 01 & Yes - 1, No- 0 \\
\hline 6 & $\begin{array}{l}\text { Form filling and } \\
\text { documentation }\end{array}$ & 01 & Yes - 1, No- 0 \\
\hline 7 & Temperature reading & 01 & Yes - 1, No- 0 \\
\hline \multicolumn{2}{|c|}{ Total score } & 09 & \\
\hline \multicolumn{4}{|c|}{ Grade- A 9-8; B 7-6; C 5-4; D 3-2; E 1-0 } \\
\hline
\end{tabular}




\section{Statistical analysis}

All the study data were double-entered into Epidataversion 3. The cleaned data were analyzed in SPSS version 20.0 (IBM Corp, Armonk, NY). All categorical variables were reported as count and percentages. Continuous variables were reported as mean and standard deviation. 'Overall Mitanins' performance' was the response variable in the analysis. Ordinal variable "Mitanins" performance was converted in to dichotomous variable (less than $B$ grade and $\geq B$ grade). As observations were paired due to matching between the groups so conditional logistic regressions was chosen. First, univariate conditional logistic regression on Mitanin's performance in relation to socio demographic determinants such as marital status, type of family, literacy rate and work experience along with Mitanins' (training plus or standard) was carried out. Then, all factors up to $p$ value 0.30 were included in the multivariate conditional logistic regression analysis to investigate the association of socio-demographic factors with Mitanins' performance after adjusting the effect of other factors.

\section{Results}

A total of 162 Mitanins (81 in each group) were interviewed. Most were married (90.3\%), above 35 years of age $(61.7 \%)$ and staying in nuclear family (52.5\%). On an average, Mitanins visited nearly 50 households every week with serving population of $\sim 250$. Nearly two third of the Mitanins had primary level of education (69.8\%) and literacy rate was $62.3 \%$.

A majority of the respondents said that focus group discussion $(70.4 \%)$ was held, and half of the study participants (50\%) asserted that village meeting were conducted during recruitment of Mitanins in the respective villages. Among all participants, only a few (14.2\%) had prior experience of any kind of community level health work. The majority of the Mitanins (51.9\%) stated "pressure from family and relatives" as a major reason for joining the Mitanin program compared to "support village health facilities" (22.2\%). Both the groups namely the training plus and standard group were comparable, except in literacy $(72.8 \%$ vs. $50.6 \%)$ and education $(80.2 \%$ vs. $59.2 \%$ ), in terms of baseline socio-demographic characteristics as shown in Table 2.

Overall performance of Mitanins' between the groups.

Table 3 shows the difference in factors and overall performance of Mitanins in both IIR and non- IIR groups. In univariate conditional logistic regression, all individual evaluating factors except slide preparation $(p=0.165)$ and documentation $(p=0.122)$, IIR Mitanins have shown better performance compared with non-IIR Mitanins. In backward conditional logistic regression, educational qualification $(p=0.017)$, knowledge about malaria (0.037), and temperature measurement $(p<0.001)$ were remain as significant factors in the final model.

Table 2 Baseline socio-demographic characteristics of Mitanins $(N=162)[\| R(n=81)$ : non $\| R(n=81)$

\begin{tabular}{|c|c|c|c|c|}
\hline \multirow[t]{2}{*}{ Variable } & \multirow[t]{2}{*}{ Category } & \multirow{2}{*}{$\begin{array}{l}\text { IIR } \\
n(\%)\end{array}$} & \multirow{2}{*}{$\begin{array}{l}\text { Non- IIR } \\
n(\%)\end{array}$} & \multirow{2}{*}{$\begin{array}{l}\text { Total } \\
n(\%)\end{array}$} \\
\hline & & & & \\
\hline Age & $\geq 35$ years & $31(38.3)$ & $31(38.3)$ & $62(38.3)$ \\
\hline Marital status & Married & 74 (91.4) & $72(88.9)$ & $146(90.1)$ \\
\hline \multirow[t]{3}{*}{ Family type } & Nuclear & $38(46.9)$ & $47(58)$ & $85(52.5)$ \\
\hline & Extended nuclear & $13(16)$ & $10(12.3)$ & $23(14.2)$ \\
\hline & Joint & $30(37)$ & $24(29.6)$ & $54(33.3)$ \\
\hline Education & $\geq$ Primary education & $65(80.2)$ & $48(59.2)$ & $113(69.7)$ \\
\hline Literacy & Read and write & $59(72.8)$ & $41(50.6)$ & $100(61.7)$ \\
\hline Household visit / week & Mean $( \pm S D)$ & $52( \pm 42)$ & $42( \pm 68)$ & $47( \pm 57)$ \\
\hline Serving population & Mean $( \pm S D)$ & $255( \pm 134)$ & $206( \pm 147)$ & $231( \pm 142)$ \\
\hline Focus group discussion held prior to join Mitanin program & Yes & $54(66.7)$ & $60(74.1)$ & $114(70.4)$ \\
\hline Village meeting held prior to join Mitanin program & Yes & $38(33.3)$ & $43(53.1)$ & $81(50)$ \\
\hline Prior work experience & Yes & $14(17.3)$ & $09(11.1)$ & $23(14.2)$ \\
\hline \multirow[t]{6}{*}{ Primary reason of join Mitanin program } & Financial incentives & $04(4.9)$ & $04(4.9)$ & $08(4.9)$ \\
\hline & Opportunity to learn & $07(8.6)$ & $06(7.4)$ & $13(8)$ \\
\hline & Support village health facilities & $23(28.4)$ & $13(16)$ & $36(22.2)$ \\
\hline & Social prestige & $01(1.2)$ & $01(1.2)$ & $02(1.2)$ \\
\hline & Pressure from family and relatives & $37(45.7)$ & $47(58)$ & $84(51.9)$ \\
\hline & Other & $9(11.1)$ & $10(12.3)$ & 19 (11.7) \\
\hline
\end{tabular}


Table 3 Performance of Mitanins in individual factors between the groups

\begin{tabular}{|c|c|c|c|c|c|}
\hline SI no. & Evaluation factor & $\begin{array}{l}\| \mathrm{R} \\
(n=81)\end{array}$ & $\begin{array}{l}\text { Non- IIR } \\
(n=81)\end{array}$ & $\begin{array}{l}\text { Unadjusted } \\
P \text { value }\end{array}$ & $\begin{array}{l}\text { Adjusteo } \\
P \text { value }^{\#}\end{array}$ \\
\hline 1 & Basic educational qualification & $65(80.2)$ & $48(59.3)$ & 0.003 & 0.017 \\
\hline 2 & Level of knowledge about malaria & & & & \\
\hline 2.a & Sign \& symptoms of Malaria & $78(96.3)$ & $68(84)$ & 0.019 & 0.037 \\
\hline 2.b & Knowledge about Malaria control & $80(98.8)$ & $71(87.7)$ & 0.028 & \\
\hline 3. & Slide preparation & 80 (98.8) & $77(95.1)$ & 0.165 & 0.066 \\
\hline 4. & RDT preparation & 74(91.4) & $62(76.5)$ & 0.020 & - \\
\hline 5. & Knowledge about anti-malarial drugs $(P \vee$ and $P f)$ & $69(85.2)$ & $51(63)$ & 0.002 & - \\
\hline 6. & Forms filling \& documentation & $35(43.2)$ & $26(32.1)$ & 0.122 & - \\
\hline 7. & Temperature measurement & $68(83.9)$ & 27 (33.3) & $<0.001$ & $<0.001$ \\
\hline
\end{tabular}

*Univariate conditional logistic regression

\#Backward conditional logistic regression (step 5), $P$ value less than 0.05 are statistically significant

Mitanins performance after adjusting with sociodemographic determinants

Table 4 illustrates the results of univariate and multivariate conditional logistic regression analysis. IIR group Mitanins performance were significantly better than non-IIR group after adjusting for socio-demographic determinants such as age, family type, marital status, literacy rate and prior work experience $(p<0.001)$.

\section{Major challenges for the Mitanins to perform their work} In the analysis of In-depth interview, five major themes appeared and subsequently placed into framework analysis. It suggests that 'lack of support from superior staff', 'delayed payments,' 'lack of appreciation,' 'less incentive', and 'intermittent medicine supply' were major challenges for Mitanins which may affect their routine work (Table 5).

\section{Discussion}

ASHA's and Mitanins are an essential cornerstone of the National Health Mission (NHM) program of India. They are well accepted by the community not only because they are part of them but also due to their accountability to the communities for their health-related activities [1].

\section{Overall demographic and educational characteristics}

An accomplishment of the Mitanin programme largely relies on the individual Mitanin to support for and provide awareness related the meaning and necessity of healthy practices among serving the population. Minimum education level and representation of the local people are key selection criteria if we desire the Mitanin to retain and communicate information to their community members. However, our study showed that nearly $30 \%$ of the Mitanins did not have the basic educational qualification. This could affect the NHM program and criteria of basic education. There could be several plausible reasons such as non-availability of literate women in the study villages or reluctance by the young educated girls to join the Mitanin program. Similar findings were reported in a study by Shrivastava et al., 2012 [16]. As per the NHM-ASHA guidelines-2005, [8] the age of the

Table 4 Mitanins performance after adjusting with socio-demographic determinants $(n=162)$

\begin{tabular}{|c|c|c|c|c|c|}
\hline Variable & Category & $\begin{array}{l}\| \mathrm{R} \\
n(\%)\end{array}$ & $\begin{array}{l}\text { Non-IIR } \\
n(\%)\end{array}$ & $\begin{array}{l}\text { Unadjusted Odds ratio } \\
(95 \% \mathrm{Cl}), P \text { value }^{*}\end{array}$ & $\begin{array}{l}\text { Adjusted Odds ratio, } \\
(95 \% \mathrm{Cl}), P_{\text {value }}^{\#}\end{array}$ \\
\hline Overall performance & $\geq B$ & $68(80)$ & $30(43.5)$ & $\begin{array}{l}6(2.53-14.24) \\
<0.001\end{array}$ & $\begin{array}{l}4.64(1.85-11.62) \\
0.001\end{array}$ \\
\hline Marital status & Married & 74(91.4) & $72(88.9)$ & $\begin{array}{l}1.4(0.44-4.41) \\
0.566\end{array}$ & - \\
\hline Family type & Nuclear & $38(46.9)$ & $47(58)$ & $\begin{array}{l}0.61(0.31-1.18) \\
0.143\end{array}$ & $\begin{array}{l}0.76(0.35-1.67) \\
0.50\end{array}$ \\
\hline Literate & Yes & $59(72.8)$ & $41(50.6)$ & $\begin{array}{l}3.57(1.55-8.26) \\
0.003\end{array}$ & $\begin{array}{l}2.28(0.87-5.96) \\
0.095\end{array}$ \\
\hline Prior work experience & Yes & $14(17.3)$ & 09 (11.1) & $\begin{array}{l}1.71(0.68-4.35) \\
0.257\end{array}$ & $\begin{array}{l}1.16(0.38-3.5) \\
0.795\end{array}$ \\
\hline $\begin{array}{l}\text { Purpose of joining Mitanin } \\
\text { program }\end{array}$ & $\begin{array}{l}\text { Financial incentives/Learning opportunity/Support } \\
\text { health facilities }\end{array}$ & $34(41.9)$ & $23(28.3)$ & $\begin{array}{l}1.79(0.93-3.44) \\
0.082\end{array}$ & $\begin{array}{l}1.75(0.794-3.84) \\
0.166\end{array}$ \\
\hline
\end{tabular}

*Univariate conditional logistic regression

\#Multivariate conditional logistic regression, $P$ value less than 0.05 are statistically significant 
Table 5 Summary of major challenges cited by Mitanins during in-depth interview

\begin{tabular}{|c|c|c|c|c|c|c|c|c|c|c|c|}
\hline \multirow[t]{3}{*}{ Sl. no. } & \multirow[t]{3}{*}{ List of major challenges } & \multicolumn{10}{|c|}{ Mitanin } \\
\hline & & \multicolumn{5}{|c|}{ IIR } & \multicolumn{5}{|c|}{ Non-IIR } \\
\hline & & 1 & 2 & 3 & 4 & 5 & 1 & 2 & 3 & 4 & 5 \\
\hline 1. & Lack of support from superior staff & $\sqrt{ }$ & & $\sqrt{ }$ & $\sqrt{ }$ & $\sqrt{ }$ & $\sqrt{ }$ & & $\sqrt{ }$ & & $\sqrt{ }$ \\
\hline 2. & Delayed payments by the govt. & $\sqrt{ }$ & $\sqrt{ }$ & $\sqrt{ }$ & $\sqrt{ }$ & $\sqrt{ }$ & $\sqrt{ }$ & $\sqrt{ }$ & $\sqrt{ }$ & $\sqrt{ }$ & $\sqrt{ }$ \\
\hline 3. & Lack of appreciation and priority treatment of cases referred by them to ANM/Hospital & $\sqrt{ }$ & & $\sqrt{ }$ & & & $\sqrt{ }$ & & $\sqrt{ }$ & $\sqrt{ }$ & \\
\hline 4. & Less incentive based on performance & $\sqrt{ }$ & $\sqrt{ }$ & $\sqrt{ }$ & $\sqrt{ }$ & $\sqrt{ }$ & $\sqrt{ }$ & $\sqrt{ }$ & $\sqrt{ }$ & $\sqrt{ }$ & $\sqrt{ }$ \\
\hline 5. & Intermittent medicine supply from the hospital & & $\sqrt{ }$ & $\sqrt{ }$ & $\sqrt{ }$ & $\sqrt{ }$ & & $\sqrt{ }$ & $\sqrt{ }$ & & $\sqrt{ }$ \\
\hline
\end{tabular}

ASHA's/Mitanins should be under 45 years. But in our study, we have observed that in some of the villages, age of the Mitanin was over 45 years. This could be a major reason for poor health care awareness in some of the area and may impact on the deliverables of government health care system in the study area.

\section{Comparative evaluation of Mitanins knowledge and efficiency of malaria surveillance work}

Comparative evaluation of both the groups of Mitanins suggested that overall, group one Mitanins (IIR) performance was significantly better than the other group. Study findings imply the rationale of additional and focused training to improve the knowledge and practices related to malaria and surveillance work. Non-IIR group Mitanins can prepare slides as better as IIR Mitanins, but the knowledge about sign, symptoms, and treatment of malaria were significantly lower than the IIR group Mitanins. Apart from being IIR Mitanins, the literacy rate is a significant determinant in unadjusted analysis. This emphasizes the importance of education for female health volunteers for efficient learning and performing the given responsibility of health care of the society.

\section{Qualitative study findings}

There are several key issues such as the financial incentive for community health workers contribute to improved motivation and performance [17]. A number of case studies have shown that regular $\mathrm{CHW}$ are more likely to engage the society in grass-roots health-related issues than the well-trained, but unpaid volunteers [18]. In India, though a nationally prescribed incentive amount an ASHA/Mitanin receives for each activity exists, but varies between the states, and may be many do not actually receive these minimum incentives. Most of the respondents feel that the incentive amount did not meet their expectations. 'Kabhi Kabhi hum man apan pass $k$ paisa la dethanbimar man la aspatal le jai bar' (Sometimes we give our own money to take the patients to the hospital) was the response by one of the Mitanin when asked how they bring patients to the hospitals during emergencies. In the year 2009, NHM Evaluation
Report submitted by Bajpai et al. [19] suggested a minimal monthly salary in addition to the work incentives. However, to date, it has not been accepted. The report also argued that the financial incentive amount should be increased as it was not commensurate to the quantum of work being performed by the ASHA's. Based on our findings, we can suggest revamping of financial incentive structure can be considered.

Secondly, many Mitanins asserted that cases referred by them get insufficient attention and they themselves receive insufficient support from the hospital staff which subsequently affects the credibility of their work among the community. Most of the Mitanins stated that they receive the intermittent medicine supply from the Govt. hospitals and is one of major barriers for routine work.

Current study was focused in one of the tribal populated malaria endemic state, Chhattisgarh in India. Results obtained from this study can be generalized but with a caution to other socio- geographic, - cultural and - demographic regions of the country.

These study findings are important for malaria control and elimination programs especially in the context of India that is going for elimination by the year 2030. This can be one of the components that needs immediate attention and also could be relevant to the countries which has similar situation for malaria control with respect to the operations and human resources for health care.

\section{Study limitations}

There are two major constraint of this study. First, as additional training is an intervention, blinding cannot possible from the participants as well as investigators. Secondly, Mitanins of both the groups usually reside in the same village and some time in proximity. Hence, there was chance of "contamination" of nonintervention arm? (i.e., Mitanins who were taught, might then teach Mitanins who were not.)

\section{Conclusion}

Constant training and supervision is backbone of capacity building of Community health workers. Mitanins 
can also be engaged for active surveillance in malaria endemic areas. Despite general training, knowledge regarding various aspects of Malaria persists. However, different challenges related to operational aspects such as receipt of material in time, delays in payment, due encouragement, multiplicity of activities etc. that hamper the efficiency of the delivery of work needs to be addressed.

\section{Abbreviations}

ANM: Auxiliary Nurse Midwifery; ASHA: Accredited Social Health Activists; CHW's: Community Health Workers; IIR: Implication of Insecticide Resistance; MSW's: Malaria Surveillance Workers; NHM: National Health Mission; Pf: Plasmodium falciparum; Pv: Plasmodium vivax; RDT: Rapid diagnostic test; SHRC: State Health Resource Center; VCN's: Volunteer Collaborator Networks; VHG: Village Health Guides; WHO: World Health Organization

\section{Acknowledgments}

We are grateful to the Mitanins (female community health workers) enrolled in the study for co-operation and having consented to participate. We would like to thank field staff for their excellent efforts in the data collection. We would also like to thank technical staff of IIR Project Field Site at Kondagaon, NIMR Field Unit, Raipur and NIMR HQ, New Delhi for their support in undertaking field activities.

\section{Funding}

Funding was provided by the Bill and Melinda Gates Foundation (Grant number OPP 1062754) which has no role in the planning, study design, data collection or writes up. This research forms part of a multi-country study coordinated by the Global Malaria Programme of the World Health Organization

\section{Availability of data and materials}

The datasets used and analyzed during the current study available from the corresponding author on reasonable request.

\section{Authors' contributions}

$K R, R M B$, and MKC designed the study. MKC, $K R$, and RMB drafted the manuscript. MKC did the literature review and study protocol preparation. MKC, GD and DKS supervised and collected the data. MKC and IK analysed the data. KR, RMB, DKS, GD, and IK reviewed and helped to write the manuscript. All authors made intellectual input to the study. All authors read and approved the final manuscript.

\section{Ethics approval and consent to participate}

The study purpose was explained in the local language to all study participants and study related queries were addressed. A written informed consent was collected from the study participants. This study was undertaken as a part of a WHO-coordinated multi-country project and ethical clearance was obtained from the Institutional Ethics Committee of National Institute of Malaria Research (ICMR), New Delhi, India (ECR/NIMR/EC/2010/75).

\section{Consent for publication}

Not applicable.

\section{Competing interests}

The authors declare that they have no competing interest.

\section{Publisher's Note}

Springer Nature remains neutral with regard to jurisdictional claims in published maps and institutional affiliations.

\section{Author details}

'National Institute of Malaria Research (ICMR) IIR-WHO Project, Field Unit, Kondagaon, Chhattisgarh, India. ${ }^{2}$ National Institute of Malaria Research (ICMR), Sector-8, Dwarka, New Delhi 110077, India. ${ }^{3}$ National Institute of Malaria Research (ICMR), Field Unit, Lalpur, Raipur, Chhattisgarh, India. ${ }^{4}$ Department of Infectious Disease Epidemiology, London School of Hygiene and Tropical Medicine, London, UK.
Received: 25 April 2017 Accepted: 4 July 2017

Published online: 11 July 2017

\section{References}

1. Witmer A, Seifer SD, Finocchio L, Leslie J, O'Neil EH. Community health workers: integral members of the health care work force. Am J Public Health 1995:85:1055-8.

2. Khan SH, Chowdhury AM, Karim F, Barua MK. Training and retaining Shasthyo Shebika: reasons for turnover of community health workers in Bangladesh. Health Care Superv. 1998;17:37-47.

3. Perry H, Zulliger R, Scott K, Javadi D. Gergen J. Examples from Bangladesh Brazil, Ethiopia, India, Iran, Nepal, and Pakistan. Matern. Child Heal. Integr. Progr: Case Studies of Large-Scale Community Health Worker Programs; 2013. http://www.mchip.net/sites/default/files/mchipfiles/17_AppB_CHW_ CaseStudies.pdf. Accessed 10 March 2016

4. WHO. The Primary Health Care Worker: Working Guide. World Health Organization (WHO), Geneva. 1987 http://apps.who.int/iris/bitstream/10665/ 38101/1/9241560975_eng.pdf. Accessed 9 April 2015.

5. Moir JS, Tullock JL, Hrbova H, Jolley DJ. Hey wood PF. Alpers MP The role of voluntary village aides in the control of malaria by presumptive treatment of fever impact on village health Papua New Guinea Med J. 1985;28:267-78.

6. Garfield RM, Vermund SH. Health education and community participation in mass drug administration for malaria in Nicaragua. Soc Sci Med. 1986;22:869-87.

7. Ruebush TK, Godoy HA. Community participation in malaria surveillance and treatment in the volunteer collaborator network of guatemala. Am J Trop Med Hyg. 1992;46:248-60.

8. Mission NRH. Meeting people's health needs in rural areas. Government of India, New Delhi: Ministry of Health and Family Welfare; 2005. http://nrhm. gov.in/publications/four-years-of-nrhm-2005-2009.html. Accessed 16 Feb 2016

9. SOCHARA. An external evaluative study of the Mitanin Programme. Final report. Society for Community Health Awareness, Research and Action (SOCHARA), Bangalore. 2005. http://www.sochara.org/sites/default/files/ mitanin Review.pdf. Accessed 9 April 2015.

10. Mishra JP. Evaluation of the community health volunteer (Mitanin) Programme. Government of Chhattisgarh: Department of Health; 2011. http://health.cg.gov.in/ehealth/MitaninFinalReport1 1thMarch2011.pdf. Accessed 5 April 2015.

11. Haider S, Adhisih V, Gupta S, Dhar N, Datta U, Manon S, et al. A rapid appraisal of sahiya in Jharkhand. Health Popul Perspect Issues. 2008;31:80-4.

12. Jain N, Srivastava NK, Khan AM, Dhar N, Manon S, Adhish V, et al. Assessment of functioning of ASHA under NRHM in Uttar Pradesh. Health Popul Perspect Issues. 2008:31:132-40.

13. Mohapatra B, Datta U, Gupta S, Tiwari VK, Nair KS, Adhish V, et al. (2008). An assessment of the functioning and impact of JananiSurakshaYojana in Orissa. Health Popul Perspect Issues. 2008;31:120-5.

14. Patel $T$, Raval $D$, Pandit N. Process evaluation of routine immunization in rural areas of Anand District of Gujarat. Health line. 2011;2:17-20.

15. Kleinschmidt I, Mnzava AP, Kafy HT, Mbogo C, Bashir Al, Bigoga J, et al. Design of a study to determine the impact of insecticide resistance on malaria vector control : a multi - country investigation. Malar J. 2015:1-13.

16. Shrivastava SR, Shrivastava PS. Evaluation of trained accredited social health activist (ASHA) workers regarding their knowledge, attitude and practices about child health. Rural \& Remote Health. 2012:12:2099.

17. Greenspan JA, McMahon SA, Chebet JJ, Mpunga M, Urassa DP, Winch PJ, et al. Sources of community health worker motivation: a qualitative study in Morogoro region. Tanzania Hum Resour Health. 2013;11:52.

18. Singh D, Negin J, Otim M, Orach CG, Cumming R. The effect of payment and incentives on motivation and focus of community health workers: five case studies from low- and middle-income countries. Hum Resour. 2015;13:58.

19. Bajpai N, Sachs JD, Dholakia RH. Improving access, service delivery and efficiency of the public health system in rural India. 2009. http:// globalcenters.columbia.edu/mumbai/files/globalcenters_mumbai/F. \%20FINAL_NRHM_Report\%202009.pdf. Accessed 10 March 2016. 